\title{
Direct Torque and Flux Control of Five-Phase Induction Motor Using Fuzzy Logic
}

\author{
D.Ghanbari ${ }^{1}$, N.R.Abjadi ${ }^{2}$, A.Ghanbari ${ }^{3}$ \\ Shahid Abbaspour Dam \& Hydro Power Plant Operation \& Generation Co, Masjedsoleiman, Iran ${ }^{1}$ \\ Department of Engineering, Shahrekord University, Shahrekord, Iran ${ }^{2}$ \\ Masjedsoleiman Dam \& Hydro Power Plant Operation \& Generation Co, Masjedsoleiman, $\operatorname{Iran}^{3}$
}

\begin{abstract}
In this paper a fuzzy logic scheme is applied for direct torque fuzzy control (DTFC) of five phase induction machine (FPIM). The proposed DTFC based on fuzzy logic technique switching table is described and compared with conventional direct torque control (DTC). The proposed fuzzy control strategy is simulated using Matlab/Simulink software. The simulation results show that DTFC method reduces torque ripple and stator flux variation and improves dynamic response.
\end{abstract}

Keywords: Five Phase Induction Motor, Fuzzy Control, Direct Torque Control

\section{INTRODUCTION}

High Phase Order (HPO) multiphase motor a type of AC motor that has been developed in the last decade and due to its advantage over the three phase motor, many scientists and researchers focus on it. Each electrical motor that have over three phase stator winding can be in HPO class. Researcher demonstrated that HPO drive motor many advantage over conventional three phase motor drives.

Multiphase Motor drives are mostly proposed for high power application such as traction and hybrid vehicles aircraft and etc. The advantage of multiphase machines, with respect to conventional three-phase machines are reduced torque pulsations, reduced dc-link harmonics, higher torque density, greater fault tolerant, improvement of the drive noise characteristic, reduction in the required rating per inverter leg and achieving a high power motor drive with a less dangerous dc-link voltage and high reliability [1-5]. Among multi-phase schemes, five-phase and six-phase schemes are more common .This paper deals with a five phase induction motor (FPIM). Induction motor (IM) has a low cost and is suitable for many manufacturing applications. In this paper a high performance FPIM drive is proposed. Induction motor drives controlled by field oriented control (FOC) have been still now employed in high performance industrial application [6], has achieved a quick torque response, and has been applied in various industrial applications instead of dc motors. Vector control method implies independent control of the torque and flux by decoupling the stator current into two orthogonal components. However, FOC is very sensitive to flux, which is mainly affected by parameter variation. For improvement the torque and flux control and speed of multi phase induction motor, some nonlinear and intelligent method such as feedback linearization, model following sliding mode, fuzzy logic and neural network are proposed [7-11]. In [9], a simple sliding mode and a fuzzy control are proposed for symmetrical six-phase IM and it is shown. Using special parameters the performance of two controllers is similar.

Copyright to IJIREEICE
A feedback linearization sliding mode controller is reported in [10]. Chattering and high control efforts are the problems of the sliding mode controller. Direct torque control (DTC) is one of the powerful methods for high performance control of motor drives. Direct Torque Control (DTC) of induction motor is a perfect simple control strategy in the field of variable speed AC motor. Its principle was first introduced by Takahashi in 1986 [12]. This method of controlling that has been progressed during past decade, is a powerful control method for motor drives, and also is very simple in its implementation thus can be considered as high performance vector controllers based on the decoupling of flux and torque. It provides a fast torque response without having to resort to the use of complex algorithms and also is robust against machine parameter variations. In this method, stator voltage vector is select according to the differences between the reference and actual values of torque and stator flux and the position of stator flux angle. The main advantages of DTC are absence of coordinate transformation and current PI regulator, its sensorless configuration and simple implementation. In DTC method, the inverter switches are directly controlled and there is no need to the special switching techniques such as (PWM, SVPWM). DTC has a very fast dynamic response. The main drawbacks of conventional DTC are high torque ripple because none of the VSI state is able to generate the exact voltage value required to make zero both the torque electromagnetic error and the stator flux error, the slow transient response to the step changes in torque during start-up, variable switching frequency that produce variable harmonics in stator current and its low performance in low speed operation. For improvement in direct torque control several methods are proposed. The Artificial Intelligence (AI) techniques, such as expert system (ES), fuzzy logic (FL) and neural network NN) have been recently applied in motor drives. The aim of AI is to model human or natural intelligence in a computer so that a computer can think intelligently like a human being. A system with 
embedded computational intelligence is often defined as an intelligent controller that has learning, self-organizing, or self-adapting capability. Computational intelligence has been progressively utilized to solve any usual and complex control problems [13-14]. With increasing the calculation power of the digital signal processors, the implementation of the more complicated controllers is feasible and a higher performance motor drive can be achieved. In this paper, with the aid of a FL scheme, the torque and flux ripples of a FPIM drive are reduced considerably.

\section{DESCRIPTION AND MODELING OF THE FPIM}

The FPIM considered has five phase windings mutually displaced in space by $72^{\circ}$ as shown in Fig.1.[15]. The windings axes of five stator winding are displaced by 72 degrees. By increasing the number of phases, it is also possible to increase the torque per ampere for the same volume machine. In this analysis the iron saturation is neglected.

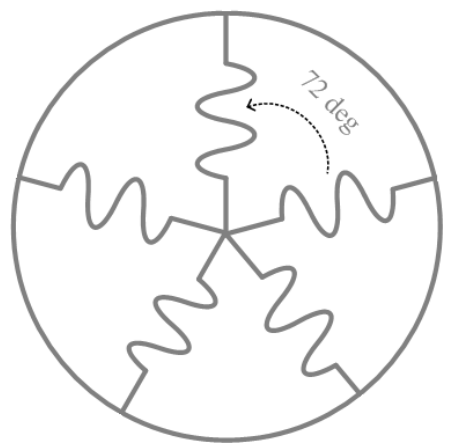

Fig. 1. Schematic representation of the FPIM

The line-to-neutral voltages can be transformed to the d-q$\mathrm{x}-\mathrm{y}-\mathrm{o}$ planes using the following transformation matrix $\mathrm{K}$ [15]:

$\mathrm{K}=$

$\left(\frac{2}{5}\right)\left[\begin{array}{ccccc}1 & \cos (2 \pi / 5) & \cos (4 \pi / 5) & \cos (4 \pi / 5) & \cos (2 \pi / 5) \\ 0 & \sin (-2 \pi / 5) & \sin (4 \pi / 5) & \sin (4 \pi / 5) & \sin (2 \pi / 5) \\ 1 & \cos (4 \pi / 5) & \cos (2 \pi / 5) & \cos (2 \pi / 5) & \cos (-4 \pi / 5) \\ 0 & \sin (4 \pi / 5) & \sin (2 \pi / 5) & \sin (2 \pi / 5) & \sin (4 \pi / 5) \\ \frac{1}{\sqrt{2}} & \frac{1}{\sqrt{2}} & \frac{1}{\sqrt{2}} & \frac{1}{\sqrt{2}} & \frac{1}{\sqrt{2}}\end{array}\right]$

The stator voltage equations of the machine in stationary frame are:

$$
\begin{gathered}
v_{d s}=R_{s} i_{d s}+\frac{d}{d t}\left(L_{s} i_{d s}+L_{m} i_{d r}\right) \\
v_{q s}=R_{s} i_{q s}+\frac{d}{d t}\left(L_{s} i_{q s}+L_{m} i_{q r}\right) \\
v_{x s}=R_{s} i_{x s}+\frac{d}{d t}\left(L_{l s} i_{x s}\right) \\
v_{y s}=R_{s} i_{y s}+\frac{d}{d t}\left(L_{l s} i_{y s}\right) \\
v_{o s}=R_{s} i_{o s}+\frac{d}{d t}\left(L_{l s} i_{o s}\right)
\end{gathered}
$$

where $R_{s}, L_{s}, L_{l s}$ and $L_{m}$ are stator resistance, stator inductance, stator leakage inductance and magnetizing inductance, respectively. The rotor voltage equations of the machine in stationary frame are

$$
\begin{gathered}
0=R_{r} i_{d r}+w\left(L_{r} i_{q r}+L_{m} i_{q s}\right)+\frac{d}{d t}\left(L_{r} i_{d r}+L_{m} i_{d s}\right) \\
0=R_{r} i_{q r}-w\left(L_{r} i_{d r}+L_{m} i_{d s}\right)+\frac{d}{d t}\left(L_{r} i_{q r}+L_{m} i_{q s}\right)
\end{gathered}
$$

where $R_{r}, L_{r}, L_{l r}$ and $\mathrm{w}$ are rotor resistance, rotor inductance, rotor leakage inductance and motor speed respectively.

The torque equation of the machine is given as follows

$$
T_{e}=p L_{m}\left(i_{d r} i_{q s}-i_{d s} i_{q r}\right)
$$

where $P$ is the number of pole pairs.

\section{FIVE PHASE VOLTAGE SOURCE INVERTER}

The five-phase voltage source inverter (VSI) contains a switching network of 10 power switches arranged to form 5 legs, each leg supplies one motor phase, Fig 2 shows the voltage source five phase inverter. Only one of the power switches of the same leg can operate in the "on" state to avoid the short circuit of the dc-link, where (Sa, Sb, Sc, Sd, Se) are switching functions of the inverter legs with value " 1 " indicates that the upper switches in the corresponding switching arms are "on", while the " 0 " indicates the "on" state of the lower switches. So, 32 possible states can be obtained. In this case, the voltages applied to the five phase induction motor are determined only by the inverter switching modes and regarded as discrete values. The machine phase voltage can be computed using the switching function associated to one inverter leg [17].

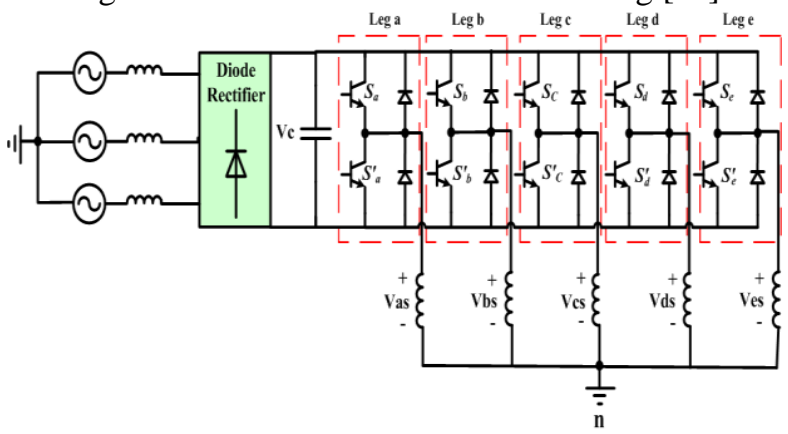

Fig. 2. Five-Phase Voltage Source Inverter

The voltage equations of five-phase voltage source inverter are:

$$
\begin{aligned}
& \mathrm{v}_{\mathrm{as}}=\left(\frac{4}{5}\right)\left(\mathrm{v}_{\mathrm{an}}\right)-\left(\frac{1}{5}\right)\left(\mathrm{v}_{\mathrm{bn}}+\mathrm{v}_{\mathrm{cn}}+\mathrm{v}_{\mathrm{dn}}+\mathrm{v}_{\mathrm{en}}\right) \\
& \mathrm{v}_{\mathrm{bs}}=\left(\frac{4}{5}\right)\left(\mathrm{v}_{\mathrm{bn}}\right)-\left(\frac{1}{5}\right)\left(\mathrm{v}_{\mathrm{an}}+\mathrm{v}_{\mathrm{cn}}+\mathrm{v}_{\mathrm{dn}}+\mathrm{v}_{\mathrm{en}}\right) \\
& \mathrm{v}_{\mathrm{cs}}=\left(\frac{4}{5}\right)\left(\mathrm{v}_{\mathrm{cn}}\right)-\left(\frac{1}{5}\right)\left(\mathrm{v}_{\mathrm{an}}+\mathrm{v}_{\mathrm{bn}}+\mathrm{v}_{\mathrm{dn}}+\mathrm{v}_{\mathrm{en}}\right) \\
& \mathrm{v}_{\mathrm{ds}}=\left(\frac{4}{5}\right)\left(\mathrm{v}_{\mathrm{dn}}\right)-\left(\frac{1}{5}\right)\left(\mathrm{v}_{\mathrm{an}}+\mathrm{v}_{\mathrm{bn}}+\mathrm{v}_{\mathrm{cn}}+\mathrm{v}_{\mathrm{en}}\right) \\
& \mathrm{v}_{\mathrm{es}}=\left(\frac{4}{5}\right)\left(\mathrm{v}_{\mathrm{en}}\right)-\left(\frac{1}{5}\right)\left(\mathrm{v}_{\mathrm{an}}+\mathrm{v}_{\mathrm{bn}}+\mathrm{v}_{\mathrm{cn}}+\mathrm{v}_{\mathrm{dn}}\right)
\end{aligned}
$$

where $n$ is the negative point of the DC link.

\section{IV.CONVENTIONAL DTC OF FPIM}

DTC of FPIM is similar to three phase induction machine [18]. The DTC of induction machine is based on direct determination of the commutation sequences of the inverter switches. It is possible to control directly the stator flux and torque by selecting an appropriate switching inverter states. The DTC scheme requires the estimation of the stator flux and torque which are compared to their reference values and the resulting errors are fed to hysteresis controllers of stator flux and torque. The purpose of the direct torque control of 
induction machine is to restrict the stator flux and torque errors within respective limits of the flux and torque hysteresis bands by an appropriate selection of the inverter switching states. The block diagram conventional DTC of FPIM is depicted in Fig.3.



Fig. 3. Conventional DTC of FPIM

The switching table DTC based on the estimated stator flux position, hysteresis controllers for torque and flux are used to generate the inverter switching states. Since the five phase voltage source inverter has $5 \mathrm{legs}$ and each switch takes 2 states (off and on), the five phase voltage source inverter has 32 switching mode.

Thirty-two switching combinations can be considered according to the transformation matrix and inverter equations, two zero voltage vectors and thirty non-zero space voltage vectors, as shown in Fig. 4. This fig shows the position of the switching vectors in $\mathrm{d}-\mathrm{q}$ plane. These voltage vectors have three different amplitudes. The switching plane is correspondingly divided into 10 sectors [15-16],[18].

As described previously, in each sampling period, the voltage vectors are selected according to the errors of stator flux and torque. The 32 voltage vectors are divided into three groups according to their amplitudes.



Fig. 4. Space Voltage Vectors of Five Phase Inverter

The vectors with the largest amplitude have the most effect on the flux and torque of the machine. Table 1 summaries the combined effects of each voltage vector on both the stator flux and torque, assuming the stator flux is located in the first sector [15].
TABLEI

Influence of voltage vectors on stator flux and torque

\begin{tabular}{|c|c|c|c|c|c|c|c|c|c|c|}
\cline { 2 - 12 } \multicolumn{1}{c|}{} & \multicolumn{10}{c|}{ Voltage Vectors } \\
\cline { 2 - 12 } \multicolumn{1}{c|}{} & $v_{9}$ & $v_{26}$ & $v_{20}$ & $v_{13}$ & $v_{10}$ & $v_{22}$ & $v_{5}$ & $v_{11}$ & $v_{18}$ & $v_{21}$ \\
\hline$T_{s}$ & $\uparrow$ & $\uparrow \uparrow$ & $\uparrow \uparrow \uparrow$ & $\uparrow \uparrow$ & $\uparrow$ & $\downarrow$ & $\downarrow \downarrow$ & $\downarrow \downarrow \downarrow$ & $\downarrow \downarrow$ & $\downarrow$ \\
\hline$\emptyset_{s}$ & $\uparrow \uparrow \uparrow$ & $\uparrow \uparrow$ & $\uparrow$ & $\downarrow$ & $\downarrow \downarrow$ & $\downarrow \downarrow$ & $\downarrow$ & $\uparrow$ & $\uparrow \uparrow$ & $\uparrow \uparrow \uparrow$ \\
\hline & $v_{16}$ & $v_{29}$ & $v_{8}$ & $v_{30}$ & $v_{4}$ & $v_{15}$ & $v_{2}$ & $v_{23}$ & $v_{1}$ & $v_{27}$ \\
\hline$T_{s}$ & $\uparrow$ & $\uparrow \uparrow$ & $\uparrow \uparrow \uparrow$ & $\uparrow \uparrow$ & $\uparrow$ & $\downarrow$ & $\downarrow \downarrow$ & $\downarrow \downarrow \downarrow$ & $\downarrow \downarrow$ & $\downarrow$ \\
\hline$\emptyset_{s}$ & $\uparrow \uparrow \uparrow$ & $\uparrow \uparrow$ & $\uparrow$ & $\downarrow$ & $\downarrow \downarrow$ & $\downarrow \downarrow$ & $\downarrow$ & $\uparrow$ & $\uparrow \uparrow$ & $\uparrow \uparrow \uparrow$ \\
\hline & $v_{25}$ & $v_{24}$ & $v_{28}$ & $v_{12}$ & $v_{14}$ & $v_{6}$ & $v_{7}$ & $v_{8}$ & $v_{19}$ & $v_{17}$ \\
\hline$T_{s}$ & $\uparrow$ & $\uparrow \uparrow$ & $\uparrow \uparrow \uparrow$ & $\uparrow \uparrow$ & $\uparrow$ & $\downarrow$ & $\downarrow \downarrow$ & $\downarrow \downarrow \downarrow$ & $\downarrow \downarrow$ & $\downarrow$ \\
\hline$\emptyset_{s}$ & $\uparrow \uparrow \uparrow$ & $\uparrow \uparrow$ & $\uparrow$ & $\downarrow$ & $\downarrow \downarrow$ & $\downarrow \downarrow$ & $\downarrow$ & $\uparrow$ & $\uparrow \uparrow$ & $\uparrow \uparrow \uparrow$ \\
\hline
\end{tabular}

Three arrows upward $(\uparrow \uparrow \uparrow)$ or downward $(\downarrow \downarrow \downarrow)$ represents the flux $\emptyset_{s}$, and torque $T_{e}$, can be increased of decreased with the most speed. The projection of the 12 largest voltage vectors generated by the inverter in (d-q) subspace and (x-y)is represented in Fig. 5. One can see if the largest vectors in d-q plane are used in DTC of FPIM, they correspond with the smallest vectors in $\mathrm{x}-\mathrm{y}$ plane. These small vectors generate small zero sequence currents.
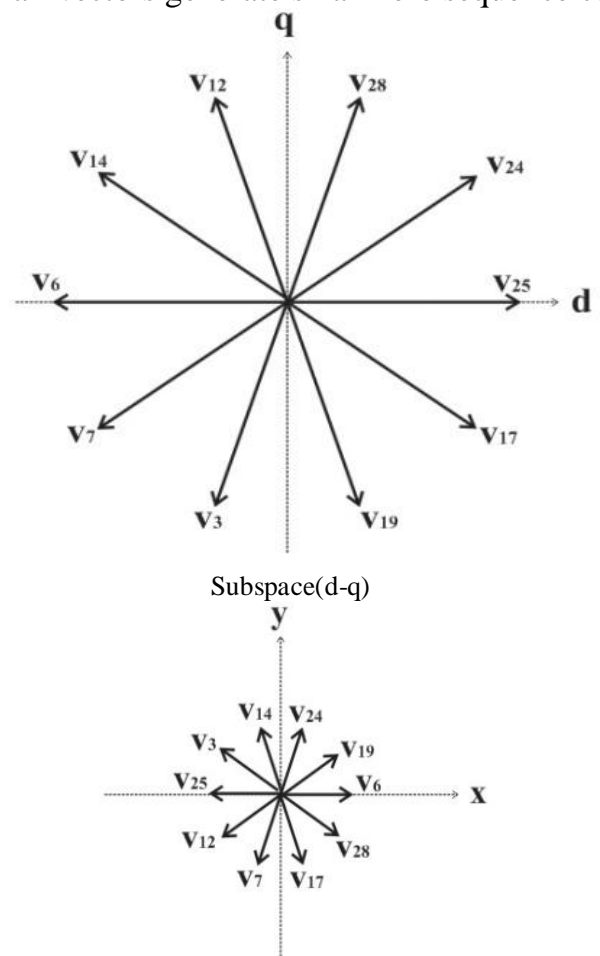

Subspace $(x-y)$

Fig. 5. The largest voltage vector in $(d-q)$ and their projection in (xy)plane

In table 2 proper voltage switching vectors for both flux and torque control are proposed.

TABLEII

Classic switching table of DTC

\begin{tabular}{|c|c|c|c|c|c|c|c|c|c|c|c|}
\hline & & \multicolumn{10}{|c|}{ sectors } \\
\hline$e_{T}$ & $\boldsymbol{e}_{\emptyset s}$ & $\mathbf{S}_{1}$ & $\mathbf{S}_{2}$ & $S_{3}$ & $S_{4}$ & $\mathbf{S}_{\mathbf{5}}$ & $\mathbf{S}_{6}$ & $\mathbf{S}_{\mathbf{7}}$ & $\mathbf{S}_{\mathbf{8}}$ & $\mathbf{S}_{9}$ & $S_{10}$ \\
\hline \multirow{2}{*}{1} & 1 & $v_{24}$ & $v_{28}$ & $v_{12}$ & $v_{14}$ & $v_{6}$ & $v_{7}$ & $v_{3}$ & $v_{19}$ & $v_{17}$ & $v_{25}$ \\
\hline & -1 & $v_{12}$ & $v_{14}$ & $v_{6}$ & $v_{7}$ & $v_{3}$ & $v_{19}$ & $v_{17}$ & $v_{25}$ & $v_{24}$ & $v_{28}$ \\
\hline \multirow{2}{*}{-1} & 1 & $v_{19}$ & $v_{17}$ & $v_{25}$ & $v_{24}$ & $v_{28}$ & $v_{12}$ & $v_{14}$ & $v_{6}$ & $v_{7}$ & $v_{3}$ \\
\hline & -1 & $v_{7}$ & $v_{3}$ & $v_{19}$ & $v_{17}$ & $v_{25}$ & $v_{24}$ & $v_{28}$ & $v_{12}$ & $v_{14}$ & $v_{6}$ \\
\hline
\end{tabular}




\section{V.PRINCIPLE OF DIRECT TORQUE FUZZY CONTROL}

The DTC using fuzzy logic control of induction motor drive is arranged with three fuzzy input variables and one output control variable. The inputs are stator flux error, electromagnetic torque error, and angle of flux stator respectively. The output is the proper voltage vector. The block diagram in Fig 6 shows the overall control system.

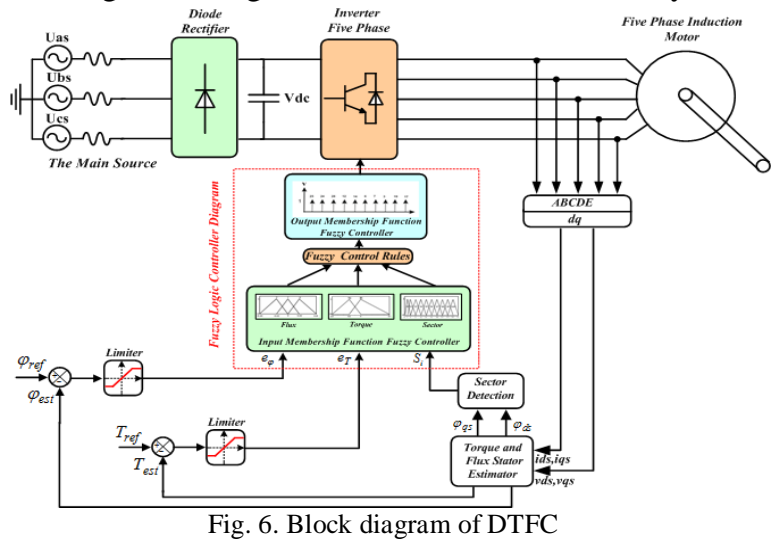

The flux linkage error is given by $\Delta \emptyset=\emptyset_{\text {sref }}-\emptyset_{s}$ where $\emptyset_{\text {sref }}$ is the reference value of stator flux and $\emptyset_{s}$ is the estimated stator flux amplitude. Three linguistic values, negative, zero and positive denoted as $\mathrm{n}, \mathrm{z}$ and $\mathrm{p}$ respectively are used to fuzzy flux linkage error domain. The torque error given by $\Delta T=T_{\text {eref }}-T_{e}$. Where $T_{\text {ref }}$ the desired torque and Te is the actual torque. Two linguistic values, negative large and positive large denoted as NL and PL, respectively are used to fuzzify the torque error. As well as, ten linguistic values, named as s1 to s10 are used to fuzzify in the domain of stator flux angle. Also , the space vector voltage: $\mathrm{i}=(25,24,28,12,14,6,7,3,19,17)$ is fuzzified using ten singleton linguistic values. The membership functions of fuzzy inputs and output are shown in Fig 7.

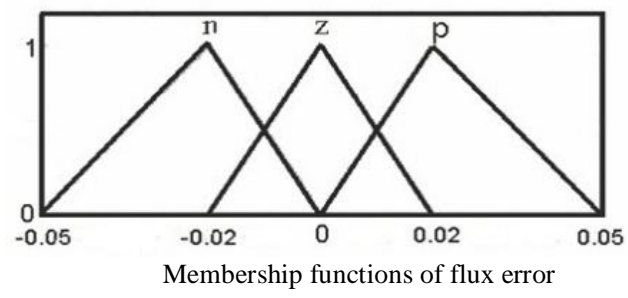

$\Delta \varphi=\varphi_{\text {sref }}-\varphi_{s}$

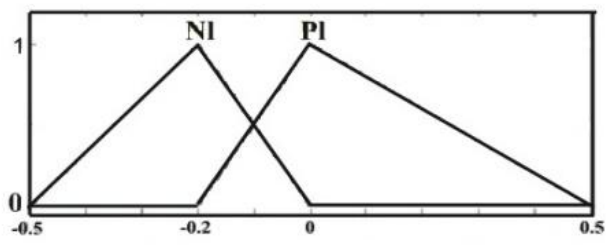

Membership functions of torque error $\Delta T=T_{\text {eref }}-T_{e}$



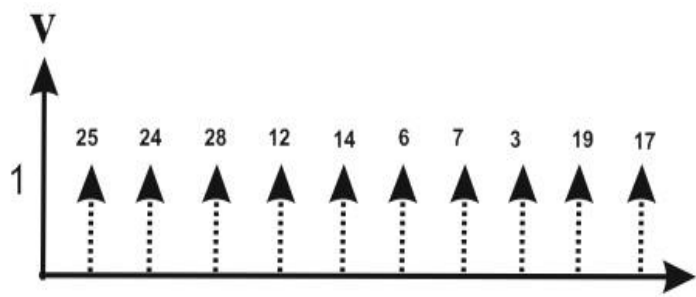

Membership functions of voltage vector

Fig. 7. Membership functions of the input and output FC

The inference method applied in this paper is Mamdani's procedure based on min-max decision. The membership functions of variables $\Delta \emptyset, \Delta T, \theta$ and $\mathrm{V}$ are given by $\mu_{\varphi}, \mu_{t e}, \mu_{\theta}$ and $\mu_{v}$ espectively. $\mu_{v}$ is twelve singleton variable and membership function singleton variable shown in equation 6 .

$$
\begin{aligned}
& \mu V_{i}(n)=\left\{\begin{array}{ll}
1 & V=v_{i} \\
0 & V
\end{array} v_{i}\right. \\
& \mathrm{n}=25,24,28,12,14,6,7,3,19,17
\end{aligned}
$$

Fuzzy min-max inference equations are given as: $\mu V_{i}^{*}(n)=\max _{i=1}^{60}\left\{\min \left(\min \left(\mu_{\varphi i}, \mu_{t e i}, \mu_{\theta \mathrm{i}}\right), \mu_{v i}\right)\right\}$

Finally, output control described by equation 8

$$
\mu V(n)=\max _{n=1}^{10}\left(\mu V_{i}^{*}(n)\right)
$$

The fuzzy rules are represented in table 3 .

\begin{tabular}{|c|c|c|c|c|c|c|c|c|c|c|c|}
\hline & & \multicolumn{10}{|c|}{ sectors } \\
\hline$e_{T}$ & $e_{\emptyset s}$ & $S_{1}$ & $S_{2}$ & $S_{3}$ & $S_{4}$ & $S_{5}$ & $S_{6}$ & $S_{7}$ & $S_{8}$ & $S_{9}$ & $S_{10}$ \\
\hline \multirow{3}{*}{ PL } & $\mathbf{p}$ & $v_{24}$ & $v_{28}$ & $v_{12}$ & $v_{14}$ & $v_{6}$ & $v_{7}$ & $v_{3}$ & $v_{19}$ & $v_{17}$ & $v_{25}$ \\
\hline & $\mathbf{n}$ & $v_{28}$ & $v_{12}$ & $v_{14}$ & $v_{6}$ & $v_{7}$ & $v_{3}$ & $v_{19}$ & $v_{17}$ & $v_{25}$ & $v_{24}$ \\
\hline & $\mathbf{z}$ & $v_{12}$ & $v_{14}$ & $v_{6}$ & $v_{7}$ & $v_{3}$ & $v_{19}$ & $v_{17}$ & $v_{25}$ & $v_{24}$ & $v_{28}$ \\
\hline \multirow{3}{*}{ NL } & p & $v_{19}$ & $v_{17}$ & $v_{25}$ & $v_{24}$ & $v_{28}$ & $v_{12}$ & $v_{14}$ & $v_{6}$ & $v_{7}$ & $v_{3}$ \\
\hline & $\mathbf{n}$ & $v_{3}$ & $v_{19}$ & $v_{17}$ & $v_{25}$ & $v_{24}$ & $v_{28}$ & $v_{12}$ & $v_{14}$ & $v_{6}$ & $v_{3}$ \\
\hline & $\mathbf{z}$ & $v_{7}$ & $v_{3}$ & $v_{19}$ & $v_{17}$ & $v_{25}$ & $v_{24}$ & $v_{28}$ & $v_{12}$ & $v_{14}$ & $v_{6}$ \\
\hline
\end{tabular}

Table III

The proposed Fuzzy Control Rules

\section{VI.SIMULATION RESULT}

Parameters of the selected FPIM are given in table 4. The sampling period of the system is $10 \mu \mathrm{s}$. Two cases are considered: DTC and DTFC. In each case, torque, flux, direct and quadratic components of stator current, motor speed are represented. The results of the several tests are shown to investigate the performance of DTC and DTFC. In Figs. 8 and 9 the torque is shown for DTC and DTFC respectively in 1 second. The torque reference is changed from 0 to $5 \mathrm{Nm}$ with a sudden step change. It can be seen the ripples in DTFC is much less than ripples in DTC for the same conditions. In Figs. 10 and 11 the torque is shown for DTC and DTFC respectively again in 1 second; but at $\mathrm{t}=0.5$ the reference torque is reversed. In these tests, the generated torque is revised from 5 to $-5 \mathrm{Nm}$ at $\mathrm{t}=0.5$ second. Again it can be seen, using DTFC the ripples are much less than ripples in DTC. Using both of DTC and DTFC, the reference torque is followed. In Figs. 12 and 13 the amplitude of stator flux is shown for DTC and 
DTFC respectively. The ripples in DTFC are obviously less than ripples in DTC. Direct and quadrature stator flux components with respect to each other in DTC and DTFC are depicted in Figs. 14 and 15 respectively. In Figs. 16 and 17 change of amplitude in flux stator is represented. To obtain these results, the flux reference is changed from $1 \mathrm{~Wb}$ to $1.2 \mathrm{~Wb}$ at $\mathrm{t}=0.5$ second. The result for DTFC in Fig. 15 is more like a circle than the result for DTC. In Figs 18 and 19 direct and quadrature stator flux components in DTC and DTFC are represented respectively corresponding to the first test (Figs. 8 and 9). The current components are sinusoidal with lower harmonics using DTFC. Final tests are considered to verify the performance of the DTC and the proposed DTCF in controlling the speed of the machine. The dynamic response speed of DTC and DTFC represent in Figs. 20 and 21 respectively. The mechanical dynamics of the machine filters the effects of torque ripples on motor speed, however the ripples in speed, using DTFC are lower than DTC. Both torque and flux of the DTC based drives are controlled in the closed-loop system without using current loops in comparison with the usual vector controlled drives.

Table IV

FPIM parameters[19]

\begin{tabular}{|c|c|c|c|}
\hline Poles & 4 & Rs & $10 \Omega$ \\
\hline $\mathbf{R r}$ & $6.3 \Omega$ & Ls & $460 \mathrm{mH}$ \\
\hline $\mathbf{L r}$ & $460 \mathrm{mH}$ & Lm & $420 \mathrm{mH}$ \\
\hline $\mathbf{J}$ & 0.00516 & B & 0.00176 \\
\hline
\end{tabular}



Fig. 8. Motor Torque in DTC

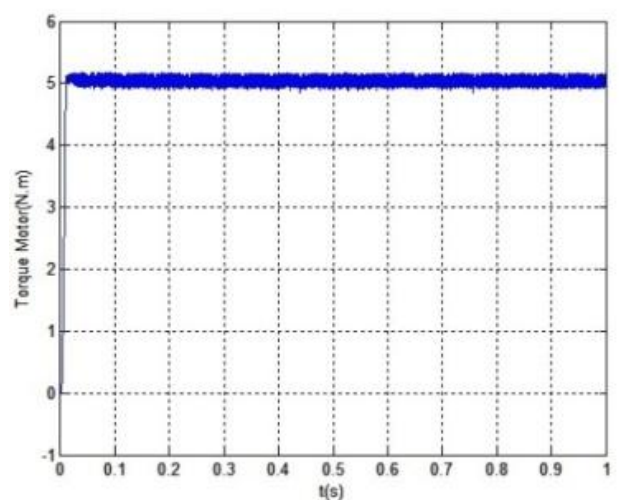

Fig. 9. Motor Torque in DTFC

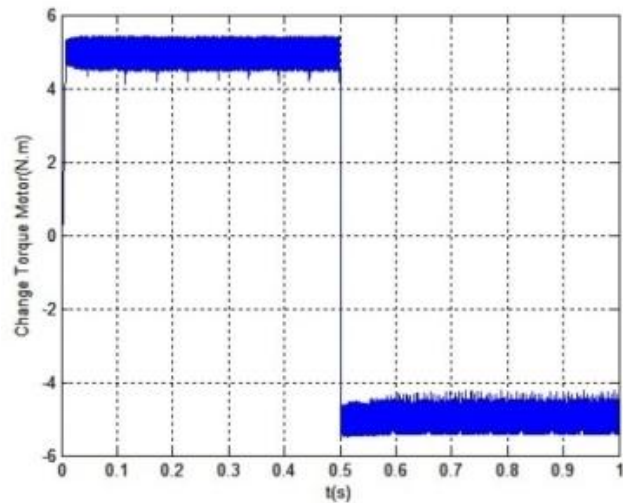

Fig.10. Change of motor Torque in DTC

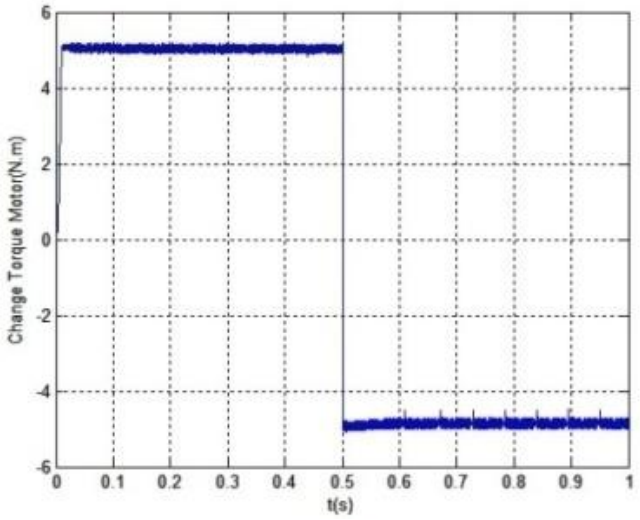

Fig. 11. Change of motor Torque in DTFC

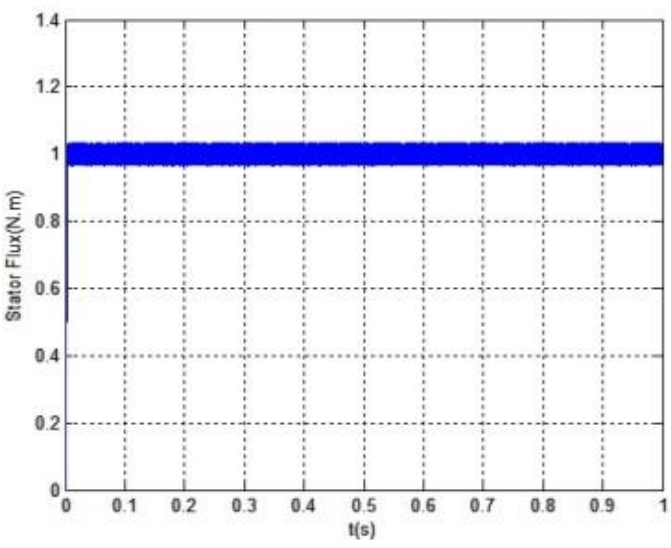

Fig.12. Stator Flux in DTC

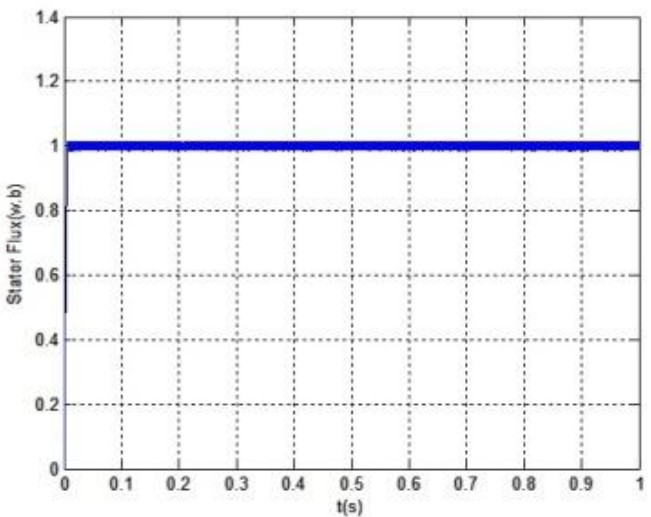

Fig. 13. Stator Flux in DTFC 


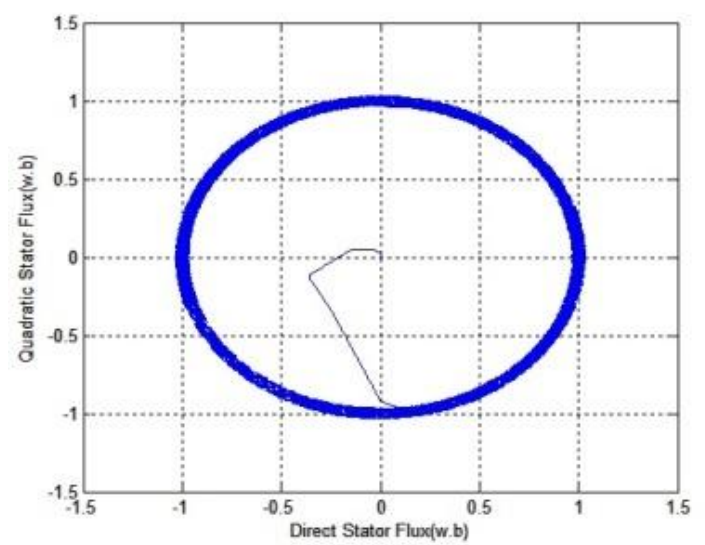

Fig. 14. Direct and quadratic stator flux in DTC

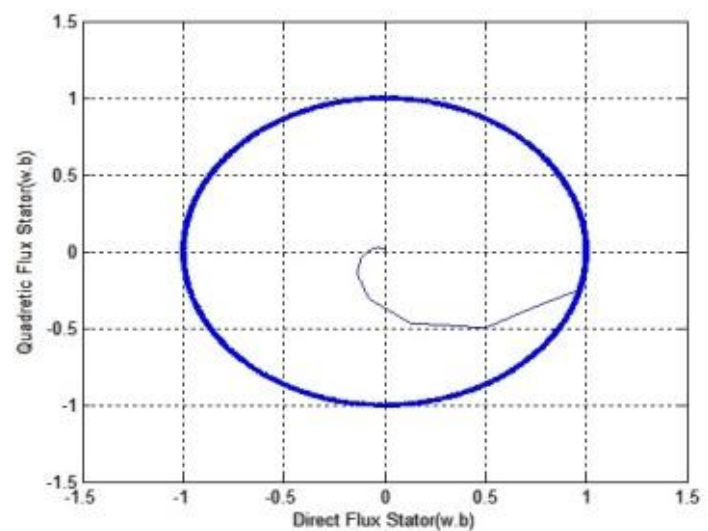

Fig.15. Direct and quadratic stator flux in DTFC

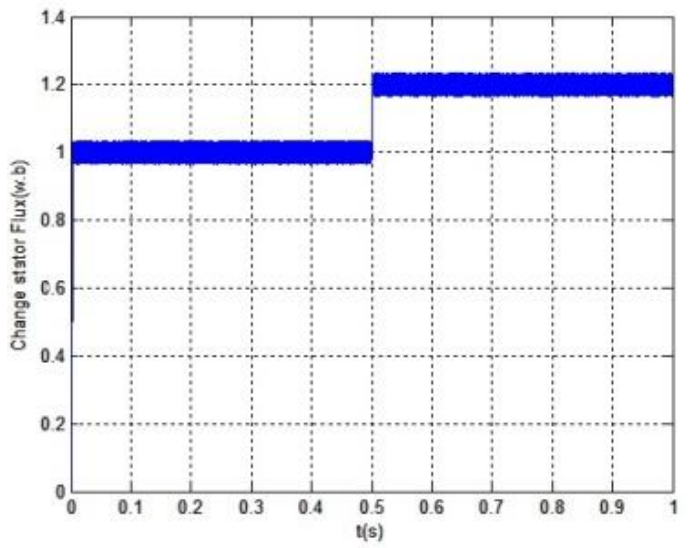

Fig.16. Change of stator flux in DTC

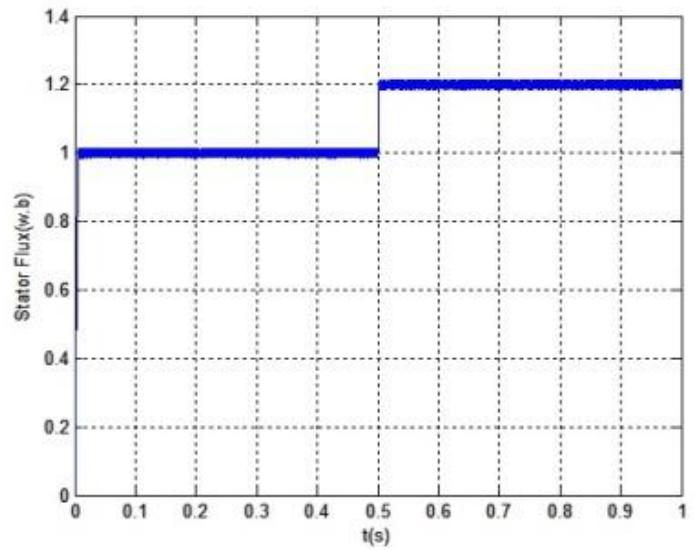

Fig. 17. Change of stator flux in DTFC

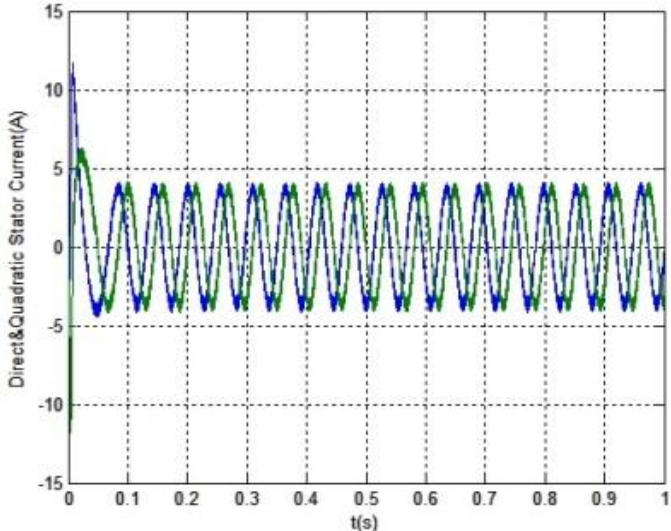

Fig.18. Direct and quadratic stator current in DTC

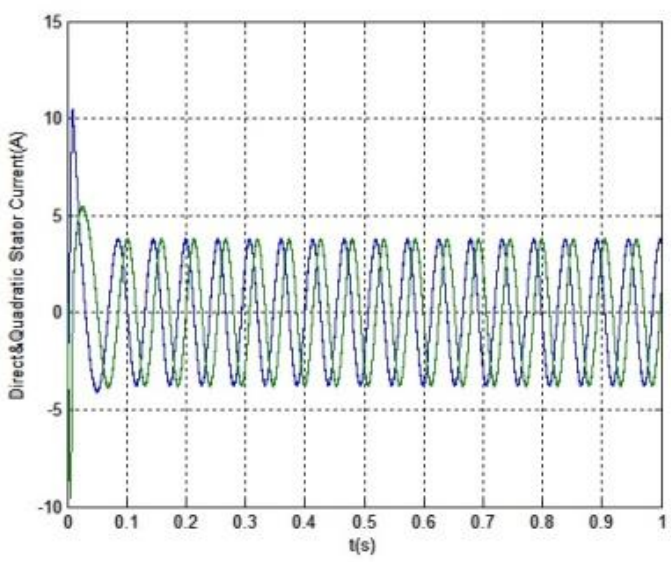

Fig. 19. Direct and quadratic stator current in DTFC

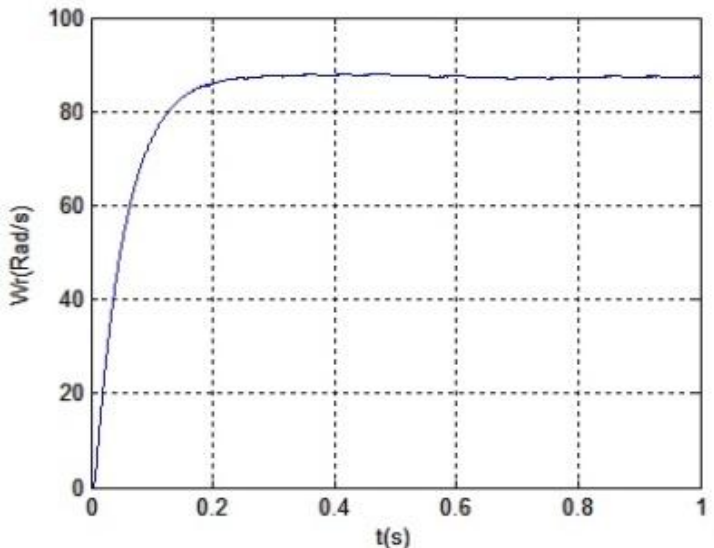

Fig. 20. Speed Motor in DTC

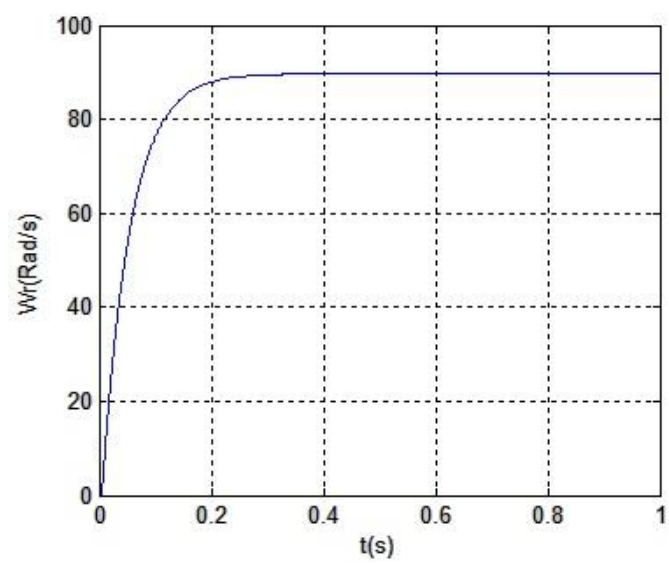

Fig. 21. Speed Motor in DTFC 


\section{CONCLUSION}

In this paper a DTC of SPIM based on fuzzy logic (DTFC) have been proposed. An improved torque and flux response is achieved with the DTFC compared to conventional DTC. The main improvements shown are:

- Reduction of torque and current and flux ripples in steady state response.

- No flux droppings caused by sector changes

circular trajectory.

- Fast stator flux response in transient state.

- Using fuzzy logic a smooth operation is achieved.

\section{REFERENCES}

[1] N.R.Abjadi, J.Soltani, Gh.Arab Markadeh, Ahmadi S.M., "Full Decoupling Control of a Sensorless Six Phase Series Connected Two Induction Motor Drive Taking into Account the Voltage - Drop of Each Motor" , International Review Electrical Engineering No. 3, May- June 2009.

[2] E.Levi, S.N. Vukosavic and M.Jones, "Vector control schemes for series - connected six-phase two - motor drive systems", IEE Proc.- Electr. Power Appl. , No. 2, March 2005.

[3] M.Jones, S.N.Vukosavic, E. Levi and A.Iqbal, " Six- Phase Series Connected Two - Motor Drive With Decoupled Dynamic Control”, IEEE Trans. on Ind. Appl., No. 4, July/August 2005.

[4] E.Levi, R. Bojoi, F.Profumo, H. A. Toliyat and S. Williamson, “ Multiphase induction motor drives a technology status review", IET Electr. Power Appl., No. 4, 489-516, 2007.

[5] R. Bojoi, F.Farina, F. Profumo and A.Tenconi, " Dual- Three Phase Induction Machine Drives Control a Survey”, JIEE Trans. on Industry Appl., No. 4, 420 -429, 2006.

[6] R. Bojoi , M. Lazzari, F. Profumo and A. Tenconi, "Digital Field Oriented Control for Dual-Three Phase Induction Motor Drives", IEEE Transactions on Applications, No. 3, 752-760, May / June 2003.

[7] G.R. Arab Markadeh, J.Soltani, N.R.Abjadi, M. Hajian , “ Sensorless Control of a Six - Phase Induction Motors Drive Using FOC in Stator Flux Reference Frame", World Academy of Science, Engineering and Technology, Issue 58 October 2009

[8] N.R.Abjadi, G.R. Arab Markadeh, J.Soltani , " Model Following Sliding - Mode Control of a Six-Phase Induction Motor Drive" Journal of Power Electronics (JPE), No. 6, Nov. 2010

[9] M. A. Fnaiech, F. Betin, G.A.Capolino, and F.Fnaiech, “ Fuzzy Logic and Sliding Mode Controls Applied to Six-Phase Induction Machine with Open Phases", IEEE Transaction on Ind. Electr., No. 1, 354- 364, Jan2010.

[10] J.Soltani, J . Askari, N.R . Abjadi and G.R. Arab Markadeh , "Sliding - mode control for a six - phase series - connected induction two - motor drive ", ELECTROMOTION, No. 1, 31-39, Jan.-Mar. 2008.

[11] A. Kargar, D. Ghanbari, N. R. Abjadi, K. Rahmati, "Improvement in Speed Control of a Six-Phase Induction Motor Using Fuzzy Control and Genetic Algorithm", The International Aegean Conference on Electrical Machines and Power Electronics (ACEMP) \& Electromotion Joint Conf., Istanbul-Turkey, 8-10 sep, pp. 333-338, 2011.

[12] I.Takahashi, T. Naguchi, "A new quick-response and high efficiency control strategy of an induction motor", IEEE Transaction on Industry Application , No.5, 820-827,1986.

[13] B. K.Bose, "Neural Network Applications in Power Electronics and Motor Drives "An Introduction and Perspective, IEEE Trans. on Ind. Electron, , No. 1, 14 - 33, Feb 2007.

[14] B. K. Bose , "Expert system , fuzzy logic , and neural network applications in power electronics and motion control", Proc. IEEE, 1994, 1303-1323, Aug. 1994.

[15] H. A.Toliyat, "Analysis And Simulation of Five - Phase Variable- Speed Induction Motor Drives Under Asymmetrical Connections", IEEE Transactions on Power Electronics, No. 4, 748-756 July 1998

[16] H. A.Toliyat, M. M. Rahimian, T. A.Lipo, "Analysis modeling of five phase converters for adjustable speed drive applications", proceedings of the 1993 European Conference on Power Electronics and Applications, 194 -199,1993.

[17] P. G.Sharma, S. Rangari, "Simulation of Inverter Fed Five Phase Induction Motor", International Journal of Science and Research
(IJSR), India Online ISSN: (2319-7064), Vol 2 Issue 2, February 2013.

[18] H. A.Toliyat "A novel direct torque control (DTC) method for fivephase inductionmachines" Applied Power Electronics Conference and Exposition, APEC 2000, Vol 1, pages 162-168, Feb 2000.

[19] N. R. Abjadi, J. Soltani, J. Askari, Gh. R. Arab Markadeh, "Three-Level Five-Phase Space Vector PWM Inverter for a Two Five-Phase Series Connected Induction Machine Drive"Energy and Power Engineering (EPE), pages 10-17, February 2010.

\section{BIOGRAPHIES}

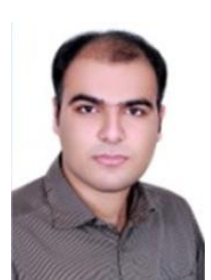

Davoud.Ghanbari was born in Ahwaz, Iran. He received the B.S in Azad Islamic University in Dezful, Iran in 2008 and M.Sc electrical engineering from the Shahrekord university, Shahrekord,Iran in 2011. His main research interest is in the area of application multi phase electric motor drives and intelligent system in general. Since 2011, He works in Shahid Abbaspour Dam \& Hydro Power Plant Operation \& Generation Co, Masjedsoleyman, Iran. Correspond Author Email: ghanbari.64@gmail.com

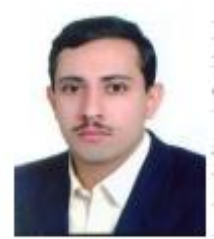

Navid R. Abjadi was born in Isfahan, Iran. He received the B. Eng. And M.Sc. degrees in electrical engineering from the Isfahan University of Technology, Isfahan, Iran, in 1999 and 2002, respectively. Since 2004, he has been working toward the Ph.D. degree at the same university. His main research interest is in the area of application of nonlinear control and electric motor drives in general.

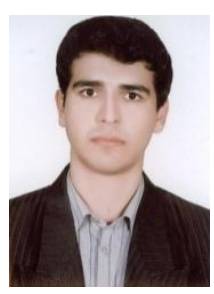

Amin.Ghanbari was born in Ahwaz, Iran. He received the B.S in Azad Islamic University in Dezful, Iran in 2007 and he works in Masjed Soleyman dam and power plant, Masjed Soleyman Iran . His main research interest is in the area of application power converter and electrical drive. 